02

\title{
Комбинационное рассеяние света молекулами красителя метилового оранжевого на поверхности кремния с ионно-синтезированными наночастицами серебра
}

\author{
(C) В.В. Воробьев ${ }^{1}$, А.М. Рогов ${ }^{1}$, Ю.Н. Осин ${ }^{1}$, Н.Н. Брандт ${ }^{2}$, В.И. Нуждин ${ }^{3}$, \\ В.Ф. Валеев ${ }^{3}$, А.Л. Степанов ${ }^{1,3}$ \\ ${ }^{1}$ Междисциплинарный центр „Аналитическая микроскопия“, \\ Казанский (Приволжский) фредеральный университет, \\ 420021 Казань, Россия \\ ${ }^{2}$ Московский государственный университет им. М.В. Ломоносова, фризический фракультет, \\ 119991 Москва, Россия \\ ${ }^{3}$ Казанский фризико-технический институт им. Е.К. Завойского Казанского НЦ РАН, \\ группа нанооптики и наноплазмоники, \\ 420029 Казань, Россия \\ e-mail: slava.v679@gmail.com
}

Поступила в редакцию 27.12.2017 г.

В окончательной редакции 27.01.2018г

\begin{abstract}
Проведено апробирование возможности применения нового синтезированного по оригинальной имплантационной нанотехнологии композиционного материала на основе пористого кремния с наночастицами серебра в качестве оптического чувствительного элемента в биологических и химических сенсорах. Показано, что регистрация малых количеств анализируемого органического вещества (красителя метилового оранжевого) возможна за счет проявления гигантского комбинационного рассеяния света при расположении молекул в ближнем электромагнитном поле наночастиц серебра.
\end{abstract}

DOI: $10.21883 / O S .2018 .05 .45941 .291-17$

\section{Введение}

В настоящее время спектроскопия комбинационного рассеяния света (КР) представляет собой один из эффективных аналитических методов исследования и обнаружения органических соединений, поскольку разность частот рассеянного и возбуждающего оптического излучения равна частоте внутримолекулярных колебаний, являющейся индивидуальной характеристикой анализируемой молекулы. Однако эффективность возбуждения КР относительно мала по сравнению, например, с флуоресценцией, что влечет за собой поиск различных решений для усиления интенсивности КР сигнала. Новые возможности метода КР открылись в 1974 году, когда М. Флейшманн предложил использовать серебряный электрод, подвергнутый анодному травлению, с целью увеличения площади поверхности для осаждения молекул пиридина [1]. При этом было обнаружено усиление сигнала КР на 6-7 порядков относительно гладкого электрода, тогда как его эффективная площадь поверхности увеличивалась только на порядок, что указывает на незначительный вклад площади поверхности. Эффект усиления КР на неровной поверхности металла был назван гигантским комбинационным рассеянием света (ГКР, SERS - Surface Enhanced Surface Scattering). Помимо шероховатой металлической подложки эффект ГКР наблюдается в системе органи- ческих веществ с наночастицами благородных металлов (серебро, золото, медь, платина). В таких наночастицах под действием поля падающей электромагнитной волны видимого диапазона возникают резонансные колебания электронов проводимости, называемые поверхностным плазмонным резонансом [2]. Вблизи металлической наночастицы возникает локально усиленное электромагнитное поле, и при расположении анализируемой молекулы в этом ближнем поле происходит увеличение интенсивности КР, т. е. наблюдается ГКР [3]. Механизм усиления КР называется электромагнитным. При этом оптический сигнал от молекул не следует путать с собственным КР металлических наночастиц вследствие возникновения в них акустических колебаний [4]. Эффективность ГКР зависит от структуры подложек с металлическими наночастицами, а также их гранулометрических параметров, типа металла ит.д. Кроме электромагнитного описания, эффект усиления КР в литературе объясняется химическим механизмом, реализуемым при адсорбции молекул на металлических наночастицах. При таком взаимодействии возможен перенос заряда между молекулой и металлической наночастицей. Численные оценки показывают, что при электромагнитном механизме усиление КР может достигать 7 порядков, в то время как при химической адсорбции не более 2-3 [5], хотя на практике в реальности сложно разделить вклады от каждого из механизмов. 
Несмотря на большое количество теоретических и экспериментальных исследований, в настоящее время продолжается поиск эффективных подложек с металлическими наночастицами, характеризуемых воспроизводимыми свойствами, для получения устойчивого ГКР сигнала [6]. Одним из распространенных химических методов формирования серебряных наночастиц в растворах с последующим нанесением на поверхность различных подложек для наблюдения ГКР является восстановление нитрата серебра цитратом натрия [7] или иммерсионное осаждение серебра [8]. Такими подходами можно получать наночастицы с разными размерами и формами: пластинки, сферы, нити, стержни, диски и др. В качестве подложек для осаждения металлических наночастиц в ряде работ используется пористый кремний, синтезированный методом анодного травления [8,9]. Недостатками химических методов являются низкая воспроизводимость синтеза наночастиц и загрязнение подложек продуктами реакций.

Близким к перечисленным методам является такой способ синтеза металлических наночастиц, как „зеленая химия“ [10]. Метод основан на восстановлении серебра белками и метаболитами, которые содержатся в биологических тканях. Биосовместимость, экологическая чистота и использование недорогих компонентов привлекательны для различных приложений. Однако неоднородность размеров и морфологии частиц, образующихся в растениях, а также проблема извлечения наночастиц из них затрудняют использование этого метода. Помимо химических методов синтеза наночастиц благородных металлов на практике активно используются и физические подходы, такие как лазерная абляция в растворе [11], электронно-лучевая литография [12], ионная имплантация [13] и др.

Целью настоящей работы является создание нового типа подложек на основе пористого кремния с наночастицами серебра физическим методом высокодозовой низкоэнергетической ионной имплантации [13-15] и оценка возможности применения такого композиционного материала для усиления КР сигнала органических соединений на примере молекул красителя метилового оранжевого.

\section{Эксперимент}

Для формирования образцов пористого кремния с наночастицами серебра (Ag:PSi) использовались кристаллические пластины кремния с ориентацией (100). Имплантация проводилась ионами серебра $\mathrm{Ag}^{+}$с энергией $30 \mathrm{keV}$ при дозе облучения $D=1.5 \cdot 10^{17} \mathrm{~cm}^{-2}$ и плотности тока в ионном пучке $J$ от 2 до $50 \mu \mathrm{A} / \mathrm{cm}^{2}$.

Распределение имплантируемых ионов серебра в кремнии по глубине образца моделировалось с помощью программы SRIM-2013 (www.srim.org). При облучении кремния ионами $\mathrm{Ag}^{+}$в приповерхностном слое происходит накопление атомов металла с максимумом статистического распределения концентрации по гауссовой кривой на глубине $R_{p} \sim 26 \mathrm{~nm}$, а разброс пробега ионов от $R_{p}$ составляет $\Delta R_{p} \sim 8 \mathrm{~nm}$. При этом толщина имплантированного слоя $\left(R_{p}+\Delta R_{p}\right)$ составляет примерно $42 \mathrm{~nm}$. Накопление ионов ведет к зарождению и росту наночастиц $\mathrm{Ag}^{+}$в кремнии, а также к аморфизации его поверхностного слоя $[13,16]$. В процессе длительной ионной имплантации вследствие ионного распыления часть наночастиц $\mathrm{Ag}$ оголяется и слегка выступает над поверхностью.

Морфология поверхности, структурный и элементный анализы композиционного материала проводились на сканирующем электронном микроскопе (СЭМ) Merlin (Carl Zeiss), оснащенном рентгенодисперсионным спектрометром Aztec X-Max (Oxford Instruments). Обработка данных структурного и элементного анализа была выполнена с помощью программного обеспечения Aztec 2.1. Программа Image Pro Plus 6.0 использовалась для построения гистограммы распределения наночастиц Ag по размерам на основании полученных СЭМизображений.

Спектры КР были измерены на конфокальном микроскопе DXR Raman Microscope (ThermoFisher Scientific). В качестве источника возбуждения КР сигнала использовался непрерывный диодный лазер, генерирующий излучение на длине волны $780 \mathrm{~nm}$ с максимальной мощностью на образце $10 \mathrm{~mW}$. Измерения проводились в диапазоне 450-1700 $\mathrm{cm}^{-1}$, а спектральное и конфокальное разрешения микроскопа были равны $3 \mathrm{~cm}^{-1}$ и $5 \mu \mathrm{m}$ соответственно. Латеральное разрешение микроскопа составляло $2 \mu \mathrm{m}$.

В качестве анализируемого органического вещества использовался раствор красителя метилового оранжевого (MO) в бидистиллированной воде при концентрации $10 \mathrm{mM}$. Капля $(100 \mu \mathrm{l})$ раствора МО наносилась на подложку Ag:PSi. Высота капли, оцениваемая в оптическом микроскопе, составляла порядка $2 \mathrm{~mm}$, а ее площадь контакта с образцом $\sim 80 \mathrm{~mm}^{2}$. Регистрация КР спектров красителя в присутствии наночастиц $\mathrm{Ag}$ проводилась при фокусировке лазерного излучения на границу раздела капля - $\mathrm{Ag}: \dot{\mathrm{PS}} \mathrm{i}$ подложка, размер лазерного пучка на поверхности образца $(\sim 1 \mu \mathrm{m})$ был заметно меньше площади капли МО.

Спектры оптического отражения подложек Ag:PSi были измерены на спектрофотометре AvaSpec-2048 (Avantes) при нормальном угле падения зондирующего и отраженного светового луча к поверхности образцов через спаренный волновод в диапазоне 200-1000 nm. Спектр поглощения водного раствора красителя МО в кювете толщиной $d=1 \mathrm{~cm}$ был определен на двухлучевом спектрофотометре Lambda 35 (Perkin Elmer) при помещении в канал сравнения идентичной кюветы с бидистиллированной водой в спектральной области от 300 до $900 \mathrm{~nm}$. 

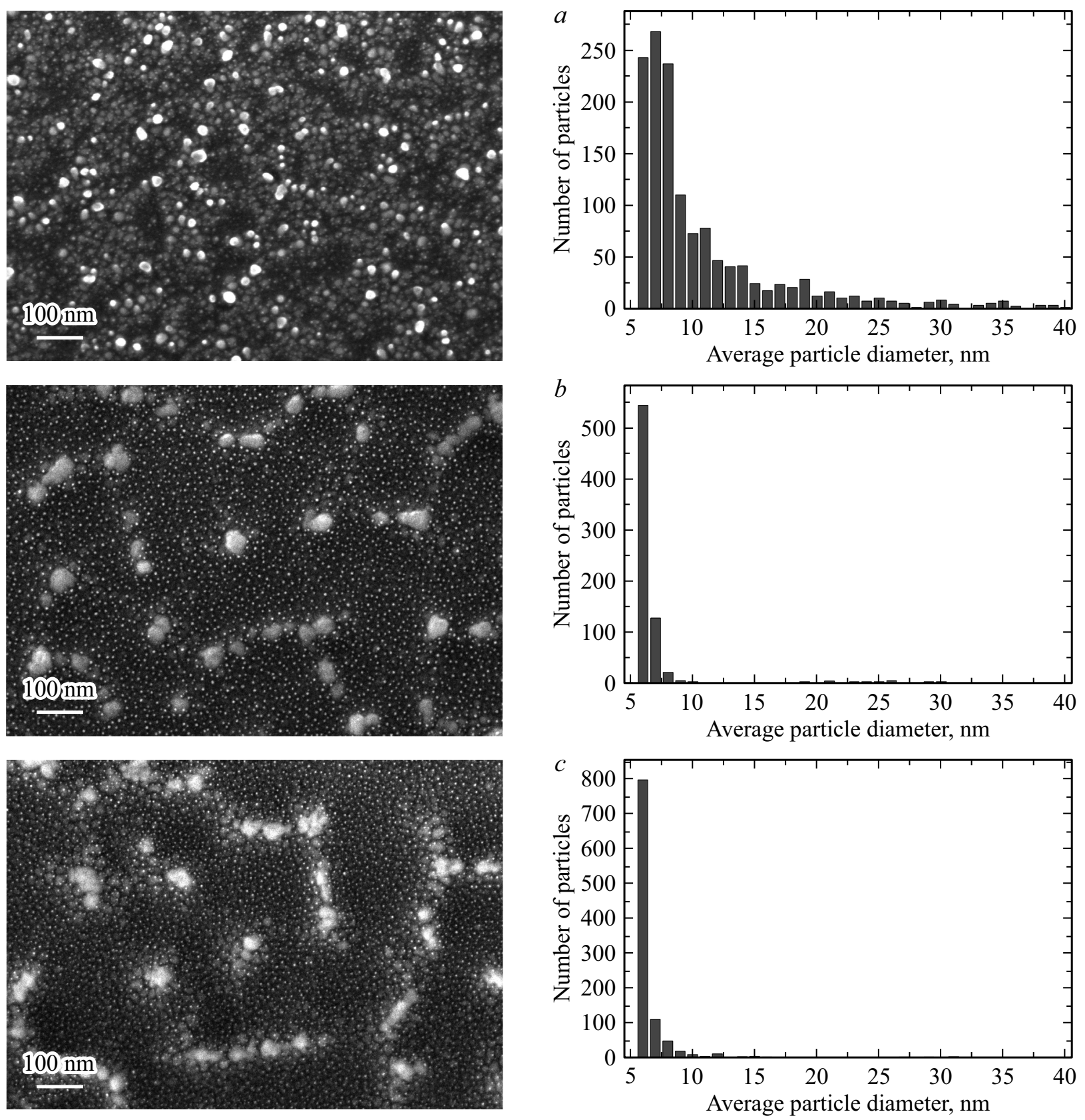

Рис. 1. СЭМ-изображения поверхности кремния, имплантированного ионами $\mathrm{Ag}^{+}$при $J(a) 2,(b) 15$ и $(c) 50 \mu \mathrm{A} / \mathrm{cm}^{2}($ слева) и соответствующие диаграммы распределения наночастиц Ag по размерам (справа).

\section{Результаты и обсуждение}

На рис. 1 приведены СЭМ-изображения образцов $\mathrm{Ag}: \mathrm{PSi}$, сформированных при различных значениях $J=2,15,50 \mu \mathrm{A} / \mathrm{cm}^{2}$. Яркие светлые пятна на темном фоне кремниевой подложки отображают ионносинтезированные наночастицы $\mathrm{Ag}$ [13-15]. На том же рис. 1 показаны гистограммы распределения наночастиц по размерам. Характерная особенность всех гистограмм заключается в наличии доминирующей фракции наночастиц с размерами $\sim 7 \mathrm{~nm}$. Концентрация наночастиц данного размера на единицу площади монотонно увеличивается для образцов с ростом $J$, тогда как разброс по размерам (ширина гистограммы) уменьшается. На всех образцах в небольшом количестве также присутствуют более крупные наночастицы с размерами $30-40 \mathrm{~nm}$, доля которых резко снижается, а средний размер повышается для бо́льших значений $J$.

В экспериментальных спектрах оптического отражения образцов Ag:PSi для всех значений $J$ наблюдается широкая полоса с максимумом вблизи длины волны $820 \mathrm{~nm}$ (рис. 2). С целью описания данного спектра 


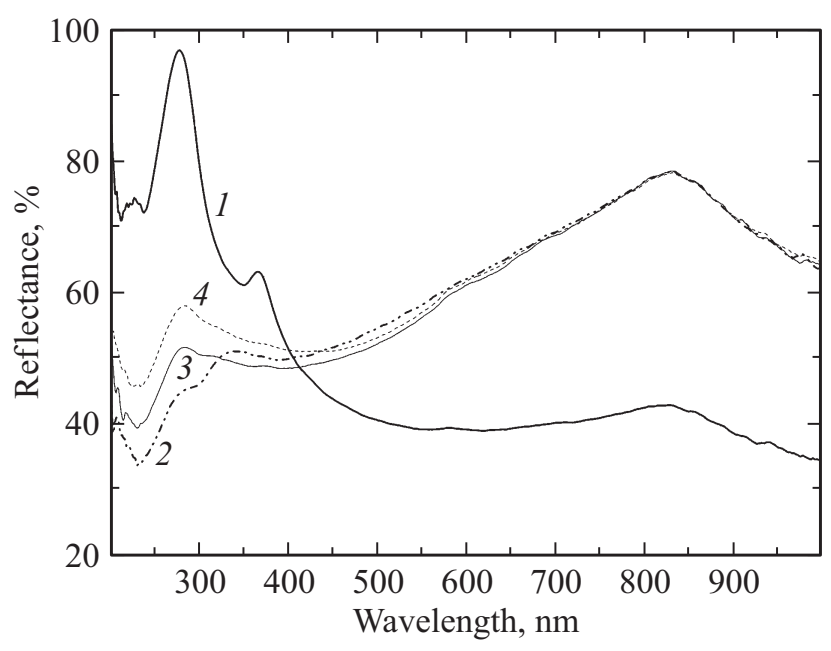

Рис. 2. Спектры отражения поверхностей кремния (1) до и после имплантации ионами $\mathrm{Ag}+\mathrm{c} D=1.5 \cdot 10^{17} \mathrm{~cm}^{-2}$ и при различных значениях $J:$ (2) 2, (3) 15 и (4) $50 \mu \mathrm{A} / \mathrm{cm}^{2}$.

было проведено моделирование спектров экстинкции, плазмонного поглощения и релеевского рассеяния для наночастиц сферической формы $\mathrm{Ag}$ с характерными размерами 7 и $40 \mathrm{~nm}$, соответствующие частицам на СЭМ-изображениях. Образование наночастиц Ag сферической формы в объеме $\mathrm{Si}$ было ранее установлено в работах [13-15].

Моделирование спектров осуществлялось по модели взаимодействия плоской электромагнитной волны со сферической частицей, находящейся в некой окружающей среде, по классической электромагнитной теории Ми $[17,18]$. Согласно этой теории, оптические сечения экстинкции и рассеяния выражаются в виде бесконечной суммы парциальных электрических и магнитных волн в сферической симметрии, создающих поля, подобные тем, как если бы частица рассматривалась в виде возбужденного мультиполя. В общем случае выражение для сечения экстинкции выглядит как

$$
\sigma_{\mathrm{ext}}=\frac{2 \pi}{\left|\mathbf{k}^{2}\right|} \sum_{L=1}^{\infty}(2 L+1) \operatorname{Re}\left(a_{L}+b_{L}\right),
$$

где $\mathbf{k}$ - волновой вектор, $L-$ порядок сферического мультипольного возбуждения в частице.

Например, $L=1$ соответствует диполю, $L=2$ квадруполю и т. Д. Коэффициенты Ми $a_{L}$ и $b_{L}$ выражаются через цилиндрические функции Риккати-Бесселя $\Psi_{L}$ и $\eta_{L}$ с аргументами $m x$ или $x$. При этом $m x=\varepsilon_{\mathrm{Ag}} / \varepsilon_{\mathrm{Si}}$ отражает отношение оптических постоянных МН и окружающей их $\mathrm{Si}$ матрицы, а $x$ является размерным параметром $x=|\mathbf{k}| R, R$ - радиус частицы. Данные коэффициенты выражаются уравнениями [18]

$$
\begin{aligned}
a_{L} & =\frac{m \Psi_{L}(m x) \Psi_{L}^{\prime}(x)-\Psi_{L}^{\prime}(m x) \Psi_{L}(x)}{m \Psi_{L}(m x) \eta_{L}^{\prime}-\Psi_{L}^{\prime}(m x) \eta_{L}(x)}, \\
b_{L} & =\frac{\Psi_{L}(m x) \Psi_{L}^{\prime}(x)-m \Psi_{L}^{\prime}(m x) \Psi_{L}(x)}{\Psi_{L}(m x) \eta_{L}^{\prime}-m \Psi_{L}^{\prime}(m x) \eta_{L}(x)} .
\end{aligned}
$$

В данных теоретических расчетах были использованы комплексные значения оптических постоянных серебpa $\varepsilon_{\mathrm{Ag}}$ в видимой области спектра [19], полученные посредством экспериментальных измерений на системе малых серебряных частиц. Спектральные комплексные значения $\varepsilon_{\mathrm{Si}}$ полупроводниковой матрицы была ранее определены в работе [20].

На рис. 3 представлены расчетные спектры, из которых следует, что для наночастиц малых размеров спектр экстинкции обусловлен исключительно их плазмонным поглощением, при этом рассеяние практически отсутствует. Поэтому вблизи малых Ag наночастиц присутствует эффективное плазмонное электромагнитное поле. В то же время для крупных наночастиц экстинкция в большей мере обусловлена рассеянием, которое доминирует над плазмонным поглощением. Отметим также, что, как следует из СЭМ-изображений образцов (рис. 1), доля крупных наночастиц по сравнению с мелкими оказывается заметно незначительной. Поэтому можно предполагать, что вклад от крупных частиц в
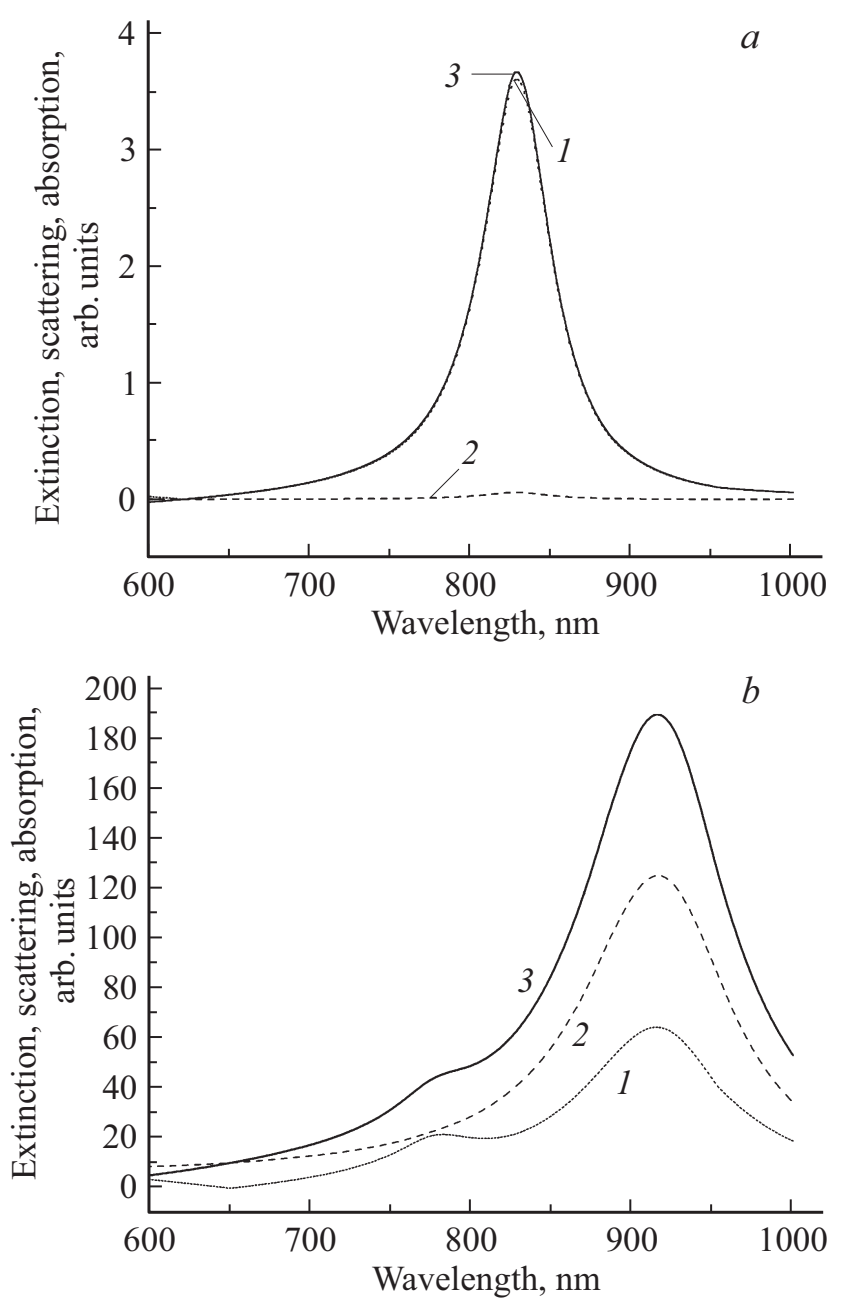

Рис. 3. Расчетные спектры плазмонного поглощения (1), релеевского рассеяния (2) и экстинкции (3) для наночастиц $\mathrm{Ag}$ диаметром $7(a)$ и $40 \mathrm{~nm}(b)$. 
локальное электромагнитное плазмонное поле на образцах также оказывается незначительным по сравнению с полем от малых частиц. Таким образом, как подробно обсуждается в работе [16], широкая полоса в экспериментальных спектрах отражения определяется суперпозицией полос рэлеевского рассеяния и интенсивного плазмонного отражения от наночастиц $\mathrm{Ag}$ различных размеров. При этом основной вклад в усиление локального поля происходит благодаря мелким $(7-10 \mathrm{~nm})$ наночастицам. Отметим также, что для близкой по составу системы субмикронных агломератов серебра на поверхности пористого кремния, синтезированного химическими методами для наблюдения КР органических молекул [6], авторы в экспериментальных спектрах отражения образцов не смогли зарегистрировать присутствие селективных полос плазмонного отражения от серебряных структур, и поэтому ошибочно считают наличие плазмонного резонанса причиной некоторых наблюдаемых ими спектральных провалов интенсивности, расположенных в ультрафиолетовой области, взамен повышенного отражения металлических наночастиц.

В спектре поглощения раствора красителя МО наблюдается полоса с максимумом на длине волны $465 \mathrm{~nm}$ (рис. 4). Оптическая плотность раствора с концентрацией $10 \mathrm{mM}$ на длине волны $780 \mathrm{~nm}$ составляет 0.035 [21]. Следовательно, для капли высотой $2 \mathrm{~mm} \mathrm{c}$ концентрацией $10 \mathrm{mM}$ при возбуждении КР спектров на длине волны $780 \mathrm{~nm}$ оптическая плотность будет равна $1.75 \cdot 10^{-3}$, и потеря мощности возбуждающего лазерного излучения при его прохождении от поверхности капли до границы раздела капля-подложка пренебрежимо мала $(0.4 \%)$.

Для сравнения усиления КР сигнала молекул МО для различных подложек $\mathrm{Ag}$ : $\mathrm{PSi}$, изготовленных ионной имплантацией при вариации значений $J$, КР спектры для всех образцов собраны на рис. 5. В спектрах присутствуют узкие линии на частотах 1118, 1150,

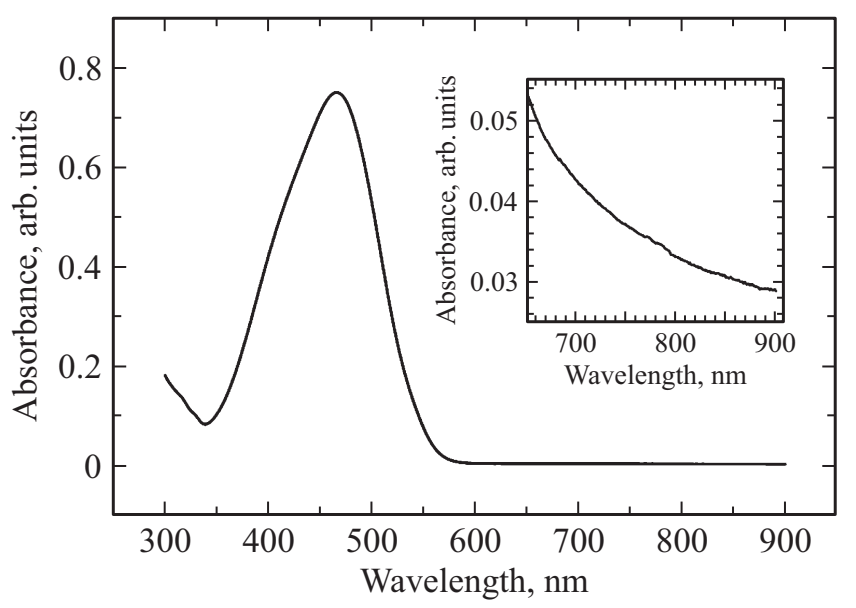

Pис. 4. Спектры поглощения водного раствора МО в концентрациях $0.1 \mathrm{mM}$ и (на вставке) $10 \mathrm{mM}$.

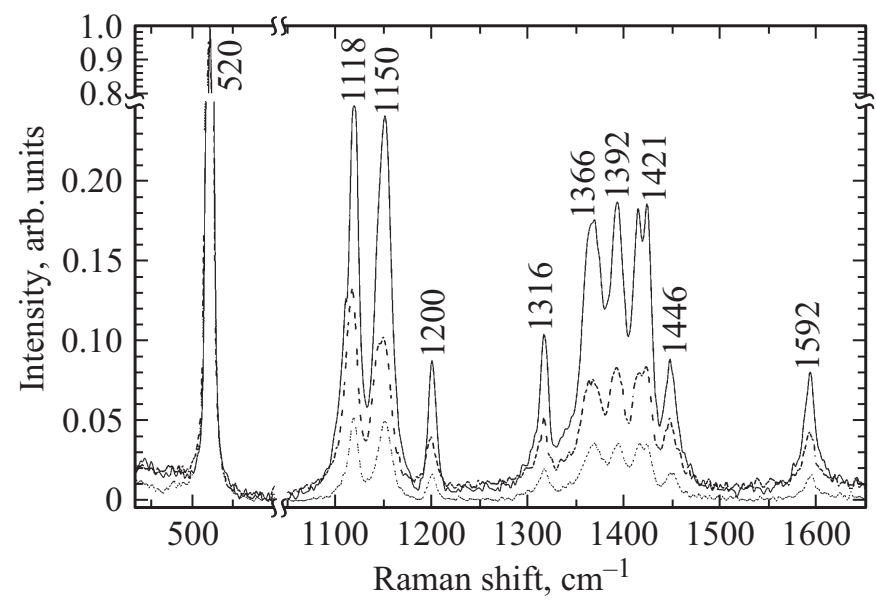

Рис. 5. КР спектры водного раствора МО (10 mM) на поверхностях образцов $\mathrm{Ag}$ : $\mathrm{PSi}$, полученных при $D=1.5 \cdot 10^{17} \mathrm{~cm}^{-2}$ и различных значениях $J: 2$ (пунктир), 15 (штриховая линия) и $50 \mu \mathrm{A} / \mathrm{cm}^{2}$ (сплошная линия).

$1200,1316,1366,1392,1421,1446$ и $1592 \mathrm{~cm}^{-1}$, соответствующие колебаниям молекул МО [22]. Все спектры КР нормированы на интенсивность фононной линии кристаллического c-Si, регистрируемой на частоте $520 \mathrm{~cm}^{-1}$, предполагая, что лазерное излучение, преодолевая имплантируемый слой, проникает в образцы на одинаковую глубину ( 10 $\mu \mathrm{m}[23])$ и зондирует одинаковый объем. При этом возбуждаемый объем заметно больше объема, занимаемого слоем кремния с наночастицами.

Из представленных экспериментальных спектров следует, что при увеличении $J$ интенсивности линий МО возрастают. Усиление интенсивности КР для образцов, изготовленных при $J=50 \mu \mathrm{A} / \mathrm{cm}^{2}$, приблизительно в 5 раз больше, чем при $J=2 \mu \mathrm{A} / \mathrm{cm}^{2}$.

Для объяснения закономерности увеличения интенсивности КР сигнала для образцов, сформированных при бо́льших значениях J (рис. 5), следует принять во внимание наличие в них совокупностей наночастиц серебра. C ростом $J$ в образцах увеличивается концентрация мелких наночастиц с размерами $\sim 7 \mathrm{~nm}$ (рис. 1), характеризуемых поверхностным плазмонным резонансным поглощением, которые генерируют ближнее электромагнитное поле. Очевидно, что увеличение количества наночастиц Ag (активных центров) а, следовательно, охваченных их полями молекул МО приводит к повышению сигнала КР. Присутствие в образцах более крупных частиц размером 30-40 nm, как это было показано выше на рис. 3, дает очень малый вклад в плазмонное поглощение, приводя лишь к интенсивному оптическому релеевскому рассеянию [13]. По-видимому, эффект усиления КР от больших частиц, характеризуемых лишь оптическим рассеянием, ниже по сравнению с малыми частицами, обладающими поверхностным плазмонным резонансом. 


\section{Заключение}

Полученные результаты на примере молекул красителя МО демонстрируют потенциальную возможность применения слоев пористого кремния с ионносинтезированными наночастицами $\mathrm{Ag}$, для усиления КР сигнала органических соединений. Проведены эксперименты на образцах, сформированных при различных значениях $J$. Наибольшее усиление сигнала КР для молекул МО было достигнуто для образцов, синтезированных при больших значениях $J$, для которых наблюдается более высокая концентрация мелких наночастиц $\mathrm{Ag}$, проявляющих поверхностный плазмонный резонанс.

Работа поддержана Российским научным фондом № 17-12-01176, Формирование слоев пористого кремния и германия с металлическими наночастицами методом ионной имплантации“ Измерения КР спектров выполнены на оборудовании, приобретенном в рамках Программы развития МГУ имени М.В. Ломоносова.

\section{Список литературы}

[1] Fleischmann M., Hendra P.J., McQuillan A.J. // Chem. Phys. Lett. 1974. V. 26. P. 163-166.

[2] Kreibig U., Volmer M. Optical properties of metal clusters. Berlin: Springer, 1995. $532 \mathrm{p}$.

[3] Акципетров O.A. // Соросовский образовательный журнал. 2001. Т. 7. № 7. С. 109-116.

[4] Курбатова Н.В., Галяутдинов М.Ф., Нуждин В.И., Валеев В.Ф., Осин Ю.Н., Степанов А.Л. // Российские нанотехнологии. 2015. Т. 3-4. С. 44-47.

[5] Набиев И.Р., Ефремов Р.Г., Чуманов Г.Д. // УФН. 1988. T. 154. № 3. C. 459-496.

[6] Terekhov S.N., Mojzes P., Kachan S.M., Mukhurov N.I., Zhvavyi S.P., Panarin A.Yu., Khodasevich I.A., Orlovich V.A., Thorel A., Grillon F., Turpin P.-Y. // J. Raman Spectr. 2011. V. 42. P. $12-20$.

[7] Yurova N.S., Markina N.E., Pozharov M.V., Zakharevich A.M., Rusanova T.Yu., Markin A.V. // Collois Surf. A: Physicochem. Eng. Aspects. 2016. N 495. P. 169-175.

[8] Panarin A.Yu., Terekhov S.N., Kholostov K.I., Bondarenko V.P. // Appl. Surf. Sci. 2010. N 256. P. 6969-6976.

[9] Yen-Chen Maggie Liou, Jiann-Yeu Chen, Jyisy Yanga // Apl. Spectr. 2014. 68. N 2. P. $172-178$.

[10] Zeiri L. // J. Raman Spectr. 2007. V. 38. P. 950-955.

[11] Neddersen J., Chumanov G., Cotton T.M. // Apl. Spectr. 1993. V. 47. N 12. P. $1959-1964$.

[12] Peters R.F., Gutierrez-Rivera L., Dew S.K., Stepanova M. // J. Visual. Exper. 2015. V. 97. e52712. P. 1-17.

[13] Степанов А.Л. Фотонные среды с наночастицами, синтезированные ионной имплантацией. Саарбрюккен. Lambert Acad. Publ, 2014. 353 c.

[14] Stepanov A.L., Nuzhdin V.I. , Valeev V.F., Vorobev V.V., Kavetskyy T.S., Osin Y.N. // Rev. Adv. Mat. Sci. 2015. V. 40. P. $155-164$.
[15] Степанов А.Л., Нуждин В.И., Валеев В.Ф., Осин Ю.Н. Способ изготовления пористого кремния при ионной имплантации. Патент на изобретение РФ, № 2547515 , 2015.

[16] Степанов А.Л., Воробьев В.В., Нуждин В.И., Валеев В.Ф., Осин Ю.Н. // ЖПС. 2017. Т. 84. № 5. С. 726-730.

[17] Mie G. // Ann. Phys. 1908. V. 25. P. 377-422.

[18] Борен К., Хаффмен Д. Поглощение и рассеяние света малыми частицами. М.: Мир, 1980.

[19] Quinten M. // Z. Phys. B. 1996. V. 101. P. 211-217.

[20] Palik E.D. Handbook of optical constants of solids. London: Academic Press. 1997.

[21] Лакович Д.Ж. Основы флуоресцентной спектроскопии. М.: Мир, 1986. 496 c.

[22] Zhang A., Fang Y. // J. Colloid Interf. Sci. 2007. 305b. P. 270-274.

[23] Двуреченский А.В., Качурин Г.А., Нидаев Е.В., Смирнов Л.С. Импульсный отжиг полупроводниковых материалов. М.: Наука, 1982. 208 с. 